\title{
Kinetic Difference between Acetate and Propionate Pregrown Reactors through Batch Methanogenesis Experiments
}

\author{
ZHENYA ZHANG ${ }^{1}$, YINGNAN YANG ${ }^{1}$, ZHONGFANG LEI ${ }^{2 *}$, HONGJIE CHEN ${ }^{1}$, \\ and NORIO SUGIURA ${ }^{1}$ \\ ${ }^{1}$ Graduate School of Life and Environmental Sciences, University of Tsukuba \\ /1-1-1 Tennodai, Tsukuba 305-8572, Japan \\ ${ }^{2}$ Department of Environmental Science and Engineering, Fudan University \\ /220 Handan Road, Shanghai 200433, China
}

\begin{abstract}
Two pregrown inocula, pre-acclimated to acetate and propionate respectively and mainly composed of coccus, diplococcus-shaped Methanosarcina-like cells and a few filamentous Methanothrix-like cells, were used separately in batch experiments to investigate the effects of varied initial acetate or propionate concentrations on methanogenesis of mixed acetate and propionate substrate under controlled neutral $\mathbf{p H}$ and $35 \pm 1{ }^{\circ} \mathrm{C}$ conditions. The results indicated that acetate pregrown systems exhibited excellent and stable degradation potentials for acetate, with maximum specific substrate degradation rate $\left(q_{\max }\right)$ ranging from 1100 to $1900 \mathrm{mg} / \mathrm{g}-\mathrm{VSS} / \mathrm{d}$ when initial acetate and propionate less than $3300 \mathrm{mg} / l$ and $750 \mathrm{mg} / l$, respectively. Under the same conditions, no distinctive difference in methane production was found for both pregrown systems, with the highest methane production rates of $107-117 \mathrm{~m} / / l^{-}$-reactor/d and methane yields ranging from 0.31 to $0.36 \mathrm{l} / \mathrm{g}-\mathrm{COD}$ removed. The average acetate and propionate degradation rates obtained were $66.7-307.2$ and $3.8-86.0 \mathrm{mg} / l-$ reactor/d and $26.7-265.7$ and $5.8-92.0 \mathrm{mg} / l-$ reactor$/ \mathrm{d}$ for acetate pregrown and propionate pregrown systems, respectively, which were found to have some negative correlations with initial propionate/ acetate(P/A) ratio (0-3.0) and initial VFA load (165.7-436.1 $\mathrm{mgCOD} / \mathrm{l}$-reactor/d), respectively. It is still a challenge to maintain and control the effectiveness of propionate degradation in pregrown systems.
\end{abstract}

Key words: pregrown inoculum, anaerobic digestion, methanogenesis, acetate, propionate

\section{INTRODUCTION}

It is well known that volatile fatty acids (VFA), mainly acetate and propionate, are important intermediary compounds in the metabolic pathway of methane fermentation and have direct correlations with digester performance, in which complex organic substances can be mineralized to methane $\left(\mathrm{CH}_{4}\right)$ and carbon dioxide $\left(\mathrm{CO}_{2}\right)$ through a series of biochemical processes involving the mediated reactions of acidogenic, acetogenic and methanogenic bacteria. Generally, the production rates of VFA are matched by their consumption rates and little accumulation could be observed under normal operations. However, imbalances are often encountered during operations or restarts of digesters because of process complexity and feed load variations, resulting in the accumulation of VFA, decrease of $\mathrm{pH}$ and even leading to the failure of digesters if no

*Corresponding author 
appropriate measures being applied in time $^{1-5)}$. Some effective solutions or strategies could be found to control and balance the production and consumption of VFA in anaerobic digesters, and such parameters as $\mathrm{pH}$, propionate/acetate $(\mathrm{P} / \mathrm{A})$ ratio, acetate and propionate concentrations, total VFA and methane production are frequently used to control and indicate the performance and normalization of digestion processes ${ }^{4-9)}$. It has been currently regarded that acetate degradation is the rate limiting step in anaerobic digestion ${ }^{10-12)}$. As generally accepted, propionate is the most difficult VFA to be removed and its level has been found to rise prior to the failure of digesters treating swine wastes ${ }^{13)}$, municipal sludge ${ }^{14)}$ and food process wastes $^{15)}$, and propionate variation could be a useful indicator of the process breakdown caused by organic overloading 12 -18 days before the decrease of methane production observed ${ }^{5}$.

It has been reported that pregrown cultures could have improved affinities for acetate or propionate if the inocula being previously contacted with acetate or glucose ${ }^{16)}$. Due to their predominant roles in the complicated and advantageous anaerobic processes, the effects of acetate and propionate on their own degradations and the interactions between both VFA are very important and now attract more interests. Still very limited information can be found.

In order to obtain more detailed information of VFA degradation potentials, the kinetic difference of acetate and propionate pregrown cultures in the methanogenesis of acetate and propionate were investigated in this paper under controlled $\mathrm{pH}$ and temperature conditions. And the effects of initial acetate and propionate concentrations and VFA loads on substrate degradation were also taken into consideration.

\section{MATERIALS AND METHODS}

Pregrown cultures Two bottles with working volume of $1000 \mathrm{~m} l$ were used for the cultivation of acetate and propionate pregrown organisms under anaerobic conditions at $35 \pm 1^{\circ} \mathrm{C}$, respectively. The anaerobic sludge used in this study was taken from Kasumigaura Wastewater Treatment Plant
(Tsuchiura, Japan), with total suspended solids (TSS), volatile suspended solid (VSS), VFA and $\mathrm{pH}$ being $11000 \pm 151 \mathrm{mg} / l, 9500 \pm 95$ $\mathrm{mg} / l, 87 \pm 15 \mathrm{mg} / l$ and $6.4 \pm 0.2$, respectively. In each bottle, the culture was made up of $20 \%$ $(\mathrm{v} / \mathrm{v})$ of anaerobic sludge $(200 \mathrm{~m} l)$ and $80 \%$ $(\mathrm{v} / \mathrm{v})$ of culture medium $(800 \mathrm{ml})$, in which acetate or propionate was added as sole carbon substrate in the following way for the pre-acclimation of methanogenic bacteria. The culture medium was composed of (per liter): $\left(\mathrm{NH}_{4}\right)_{2} \mathrm{HPO}_{4}(0.7 \mathrm{~g}), \mathrm{MgSO}_{4} \cdot 7 \mathrm{H}_{2} \mathrm{O}(0.25$ g), $\mathrm{NH}_{4} \mathrm{Cl}(0.85 \mathrm{~g}), \mathrm{KCl}(0.75 \mathrm{~g}), \mathrm{Na}_{2} \mathrm{~S}(0.001$ $\mathrm{g})$, resazurin $(0.001 \mathrm{~g})$, yeast extract $(2 \mathrm{~g})$ and $10 \mathrm{ml}$ of trace element solution. The trace element solution contained (in per liter of deionized water): $\mathrm{MgCl}_{2} \cdot 6 \mathrm{H}_{2} \mathrm{O}(4.1 \mathrm{~g})$, $\mathrm{MnCl}_{2} \cdot 4 \mathrm{H}_{2} \mathrm{O} \quad(0.5 \mathrm{~g}), \quad \mathrm{FeCl}_{2} \cdot 4 \mathrm{H}_{2} \mathrm{O} \quad(0.5 \mathrm{~g})$, $\mathrm{NiCl}_{2} \cdot 6 \mathrm{H}_{2} \mathrm{O}(0.12 \mathrm{~g}), \mathrm{ZnSO}_{4} \cdot 7 \mathrm{H}_{2} \mathrm{O}(0.1 \mathrm{~g})$, $\mathrm{CoCl}_{2} \cdot 6 \mathrm{H}_{2} \mathrm{O} \quad(0.1 \mathrm{~g}), \quad \mathrm{CaCl}_{2} \cdot 2 \mathrm{H}_{2} \mathrm{O} \quad(0.1 \mathrm{~g})$, $\mathrm{Na}_{2} \mathrm{SeO}_{3} \cdot 5 \mathrm{H}_{2} \mathrm{O}(0.08 \mathrm{~g}), \mathrm{Na}_{2} \mathrm{MoO}_{4} \cdot 2 \mathrm{H}_{2} \mathrm{O}(0.024$ g), $\mathrm{CuSO}_{4} \cdot 5 \mathrm{H}_{2} \mathrm{O}(0.01 \mathrm{~g}), \quad \mathrm{AlK}\left(\mathrm{SO}_{4}\right)_{2} \cdot 12 \mathrm{H}_{2} \mathrm{O}$ $(0.01 \mathrm{~g}), \mathrm{H}_{3} \mathrm{BO}_{4}(0.018 \mathrm{~g})$ and $\mathrm{Na}_{2} \mathrm{WO}_{4} \cdot 2 \mathrm{H}_{2} \mathrm{O}$ (0.01 g).

Before cultivation, the bottles were flushed with nitrogen gas for 2 min to exclude oxygen. After that, a gas holder was connected to each of them for the estimation of biogas production from the displaced volume of saturated $\mathrm{NaCl}$ solution. The culture was gently mixed at $60 \mathrm{rmp}$ with an electromagnetic stirrer twice a day, each for $5 \mathrm{~min}$, and its $\mathrm{pH}$ was maintained between 6.5-7.5 (adjusted with $1 \mathrm{M} \mathrm{HCl}$ or $\mathrm{NaOH}$ every day if $\mathrm{pH}$ lay beyond this range). Every other day $100 \mathrm{ml}$ of the supernatant was displaced with an equivalent volume of $10 \mathrm{~g} / l$ acetate or $5 \mathrm{~g} / l$ propionate in order to improve the tolerance of microorganisms with acetate or propionate gradually. After 3 months the culture was adapted to the concentration of acetate or propionate being used, and normal methane production was observed. The two acclimated cultures were obtained and their methane production potentials were assessed through the following batch experiments.

Batch experiments In order to investigate the performance difference between acetate and propionate pregrown cultures, two series of batch experiments were conducted in sequence, in which only one kind of VFA concentration was varied: the first series of 
experiments started at $750 \mathrm{mg} / \mathrm{l}$ of propionate with acetate varied from $200 \mathrm{mg} / \mathrm{l}$ to 8200 $\mathrm{mg} / \mathrm{l}$ in five reactors (e.g., the reactors $\mathrm{A} 1$, A2, A3, A4 and A5 were corresponded with $200,950,1650,3300$ and $8200 \mathrm{mg} / \mathrm{l}$ of initial acetate, respectively), and the second series of experiments began at $3000 \mathrm{mg} / \mathrm{l}$ of acetate with propionate varied from 0 to $2500 \mathrm{mg} / \mathrm{l}$ in five reactors (e.g., the reactors P1, P2, P3, P4 and P5 were corresponded with 0, 200, 750,1500 and $2500 \mathrm{mg} / \mathrm{l}$ of initial propionate, respectively).

For each series of experiments, $300 \mathrm{~m} l$ of acetate or propionate pregrown culture (volatile suspended solid (VSS) $=1200 \mathrm{mg} / l$ ) was divided equally into the five $500 \mathrm{~m} l$ glass reactors (with working volume of 300 $\mathrm{m} l$ ). Into each reactor $240 \mathrm{~m} l$ of culture medium was added along with a determined amount of acetate and propionate. All the initial $\mathrm{pHs}$ in them were adjusted to 6.9 and were maintained between 6.5-7.5 during the operation by the same method for pregrown cultures, and the temperatures were kept at $35 \pm 1^{\circ} \mathrm{C}$ throughout the experiments. Each reactor, connected with a gas collector, was stirred in the same way as the pregrown cultures and the operation lasted for $12-16$ days.

The concentrations of acetate and propionate and methane production were measured and recorded once every two or three days. After liquid sampling (about $5 \mathrm{ml}$ each time), an equivalent volume of culture medium was added to make the compensation of sampling loss.

Analyses and calculation The microscopic examinations of the pregrown cultures were completed with a microscope (DS-720, Topcon, Tokyo, Japan).

The components of biogas were analyzed on Shimadzu GC-8A gas chromatograph equipped with a TCD detector connected to a C-R4A CHROMATOPAC data analyzer. A stainless steel column packed with Porapak-Q was used for this purpose. The detector and injector temperature were both $60^{\circ} \mathrm{C}$ and the column temperature was $80^{\circ} \mathrm{C} . \mathrm{N}_{2}$ gas was used as the carrier gas at an inlet pressure of $199 \mathrm{kPa}$ and an outlet pressure of 150 $\mathrm{kPa}$. By this way, very accurate determination of $\mathrm{CO}_{2}$ and $\mathrm{CH}_{4}$ can be obtained.
The HP 3DCE capillary electrophoresis system, equipped with an autosampler, a chemstation and UV detector, was used to measure the concentrations of acetate and propionate (YOKOGAWA ANALYRICAL SYSTEM, Japan). Total VFA was calculated as chemical oxygen demand (COD) with conversion factors being 1.066 and 1.512 for acetate and propionate, respectively ${ }^{17)}$. It should be noted that propionate level used in $\mathrm{P} / \mathrm{A}$ ratio was as acetate. The average acetate or propionate degradation rates were obtained by the total degraded amount (mg) of acetate or propionate divided by cultivation time (d) and working volume of reactor $(\mathrm{L})$. And the biomass in the reactor was indicated by volatile suspended solid (VSS) obtained by the method of gravimetry ${ }^{18)}$. All the data present were the average values of duplicate samples.

\section{RESULTS AND DISCUSSION}

Morphology of acetate and propionate pregrown inocula After three months of cultivation with $10 \mathrm{~g} / \mathrm{l}$ of acetate or $5 \mathrm{~g} / \mathrm{l}$ of propionate as the sole carbon source, the microorganisms exhibited normal methanogenic activity with $65-80 \%$ of methane content in biogas. The microscopic observation revealed that the organisms in acetate pregrown culture were primarily composed of coccus, diplococcus-shaped Methanosarcinalike cells and a few filamentous Methanothrixlike cells (Fig. 1 (a)). The morphology was similar with the results of Yang et al. ${ }^{19}$ in fluidized bed reactor and Aguilar et al. ${ }^{16)}$ in CSTR with acetate as sole organic substrate, and resembled with the findings of Uemura and Harada $^{20)}$ in thermophilic UASB and Mösche and Jördening ${ }^{21}$ in fluidized bed reactor with acetate as main substrate. The microscopic observation was also in agreement with the morphological descriptions of these two kinds of methanogens by Lange and Ahring $^{22)}$. However, a very rich and complex flora was found in the propionate pregrown culture: some other cells with various morphologies were co-existed with the coccus, diplococcus-shaped Methanosarcina-like cells and a few filamentous Methanothrix-like cells (Fig. 1(b)), which was very similar with the finding of Aguilar et al. ${ }^{16)}$ in glucose pregrown 


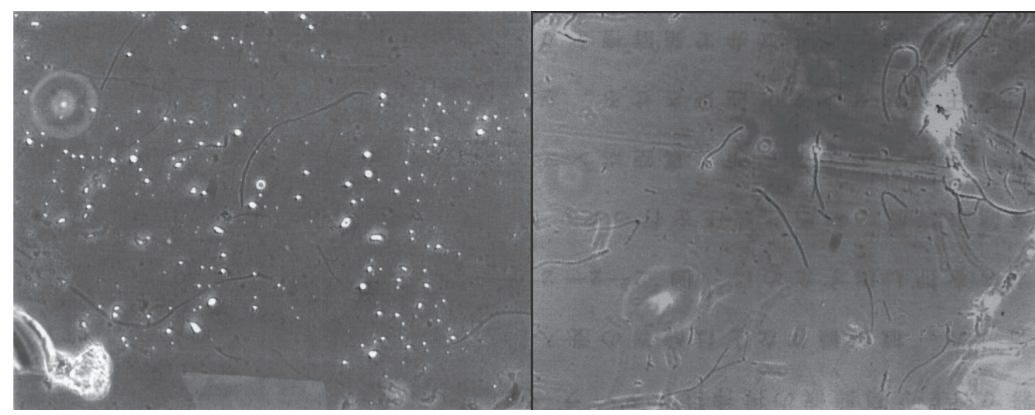

(a) Acetate pregrown

(b) Propionate pregrown

Fig. 1 Microscopic observations for pregrown inocula (magnification, $\times 200$ )

culture. The observations indicated that methanogenic propionate degradation might be completed by the coordinated action of methanogenic bacteria and other different groups.

Performance of acetate pregrown inoculum inoculated reactors Figure 2(a) depicts the progress of acetate and propionate concentrations in acetate pregrown reactors (A1-A5) under varied initial acetate concentrations and the same initial propionate levels (about $750 \mathrm{mg} / \mathrm{l}$ ). Obviously, normal methanogenesis (reactors A1-A4, Fig. 2(b)) only occurred at lower level of acetate occasions. From Fig. 2(a), it was observed that propionate degradation started only when initial acetate was almost completely degraded, which was in agreement with the results of Öztürk ${ }^{23)}$ in the first feeding treatment of acetate, propionate and butyrate mixtures with molasses-pregrown inocula and the results of Mösche and Jördening ${ }^{21)}$ in treating the acetate and propionate mixtures with anaerobic sludge from a sugar factory wastewater treatment plant.

Lag phases for propionate degradation were observed in the reactors, and the lag times seemed to be determined by initial acetate concentrations (Fig. 2(a)). About 10 to 12 days needed for the complete disappearance of $750 \mathrm{mg} / \mathrm{l}$ propionate at initial acetate levels between $200-950 \mathrm{mg} / l$. Mawson et al. ${ }^{24}$ observed the similar phenomena that the lag time depended on initial propionate degraders and initial acetate concentrations, and 10 days needed for a complete propionate degradation of 480 $\mathrm{mg} / \mathrm{l}$ at the initial acetate of $1060 \mathrm{mg} / \mathrm{l}$ by a synthetic medium-pregrown inoculum. In this study, when the initial acetate concentration was not greater than 3300 $\mathrm{mg} / \mathrm{l}$ (A1-A4), propionate began to degrade quickly after 3-day lag-period and the total VFA became less than $100 \mathrm{mg} / \mathrm{l}$ for A1-A3 occasions and less than $400 \mathrm{mg} / \mathrm{l}$ for A4 after 12 days of anaerobic digestion. No apparent inhibition on methanogenesis caused by VFA was observed, and the lag time might be shortened if the reactors were operated in continuous or semi-continuous mode due to the adaptation of the pregrown inocula to the mixture of acetate and propionate ${ }^{2)}$. In the case of $8200 \mathrm{mg} / \mathrm{l}$ of initial acetate (A5 in Fig. 2), methanogensis was inhibited completely resulting in little degradation of acetate, although propionate seemed to degrade slightly. The results agreed with the findings of Smith and $\mathrm{Mah}^{10)}$, Lawrence and McCarty $^{11)}$ and Ren et al. ${ }^{12)}$, implying that even in the acetate pregrown systems, acetate degradation was still the rate limiting step in the methanogenesis of acetate and propionate mixture.

Performance of propionate pre-grown inoculum inoculated reactors Unlike the acetate pregrown systems, lag phases were discovered for acetate degradation in propionate pregrown reactors, and about 3 days later the methane production increased largely because of the acclimation of propionate pregrown inocula to the mixed VFA substrate and the degradation of acetate 


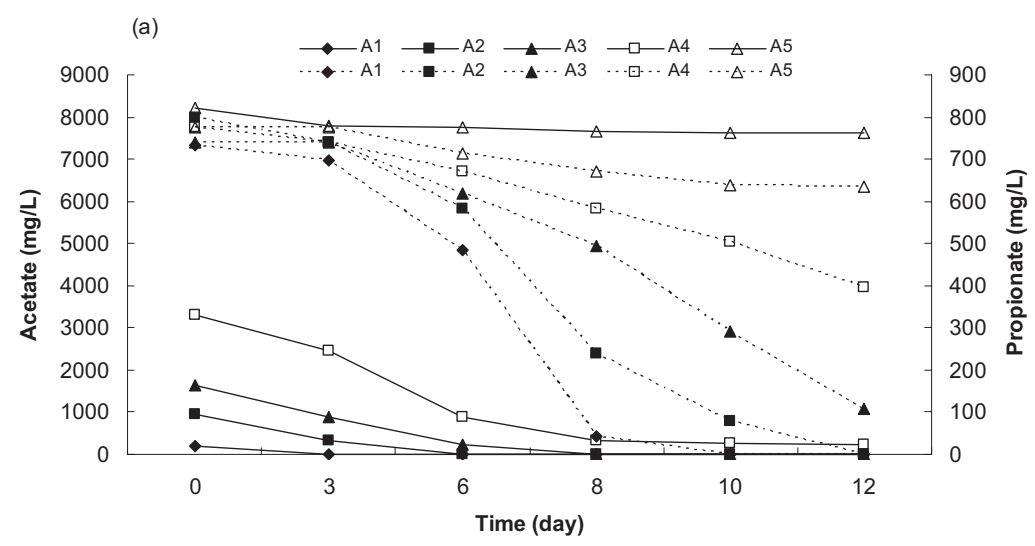

(b)

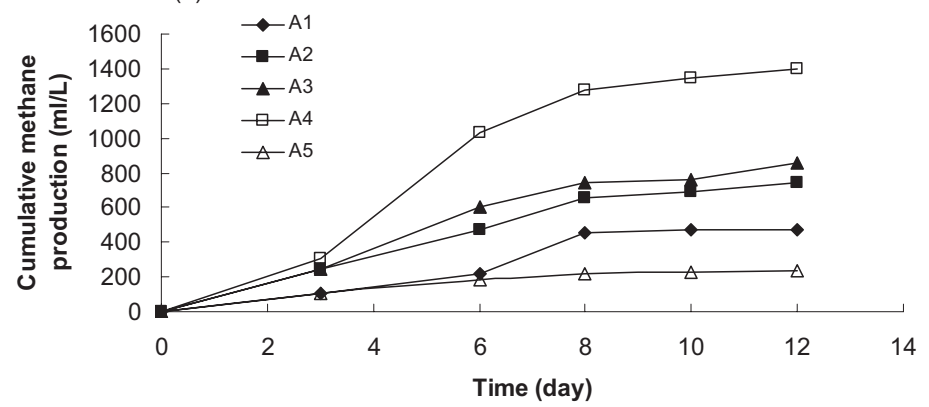

Fig. 2 Degradation curves of acetate and propionate and methane production in acetate pregrown reactors under varied initial acetate concentrations with the same initial propionate levels (about $750 \mathrm{mg} / /$ ). (a) Acetate (solid line) and propionate concentrations (dotted line), (b) Cumulative methane productions in the reactors. The initial acetate levels in the five reactors are 200(A1), 950(A2), 1065(A3), 3300(A4) and 8200 (A5) mg/l, respectively.

(Fig. 3). It is known that propionate oxidation with acetate generated is the key step for methanogenic propionate degradation. Thus, besides the adaptation period needed for propionate pregrown inoculum itself to mixed substrate, the lag phase of acetate degradation might be partly contributed by acetate generation in the instant propionate degradation, which decreased the calculation of acetate degradation if only the initial acetate being considered.

As for $8200 \mathrm{mg} / \mathrm{l}$ of initial acetate occasion (A5 in Fig. 3), similar inhibition phenomena were observed as in the corresponding acetate pregrown reactor (A5 in Fig. 2). However, some differences existed among the other four reactors (A1-A4) with respect to propionate degradation. Complete propionate degradation can be obtained for A1, A2 and
A3 at the $8^{\text {th }}, 10^{\text {th }}$ and $12^{\text {th }}$ day after digestion, respectively (Fig. 3(a)), while 10, 12 and more than 12 days were needed for the corresponding acetate pregrown reactors (Fig. 2). No lag phase of propionate degradation was observed for lower initial level of acetate conditions (A1-A2, less than $950 \mathrm{mg} / \mathrm{l}$ in this study), which was quite different from the acetate pregrown systems (Fig. 2 (a)). Under higher level of acetate conditions $(1650 \mathrm{mg} / \mathrm{l}$ in A3 and $3300 \mathrm{mg} / \mathrm{l}$ in A4 in this study), lag phases were still observed for propionate degradation.

Compared with acetate pregrown systems, propionate was found to degrade to a less level in the propionate pregrown systems after the same duration of digestion (A1-A4), although acetate degradation underwent lag period in this kind of systems. The methane 


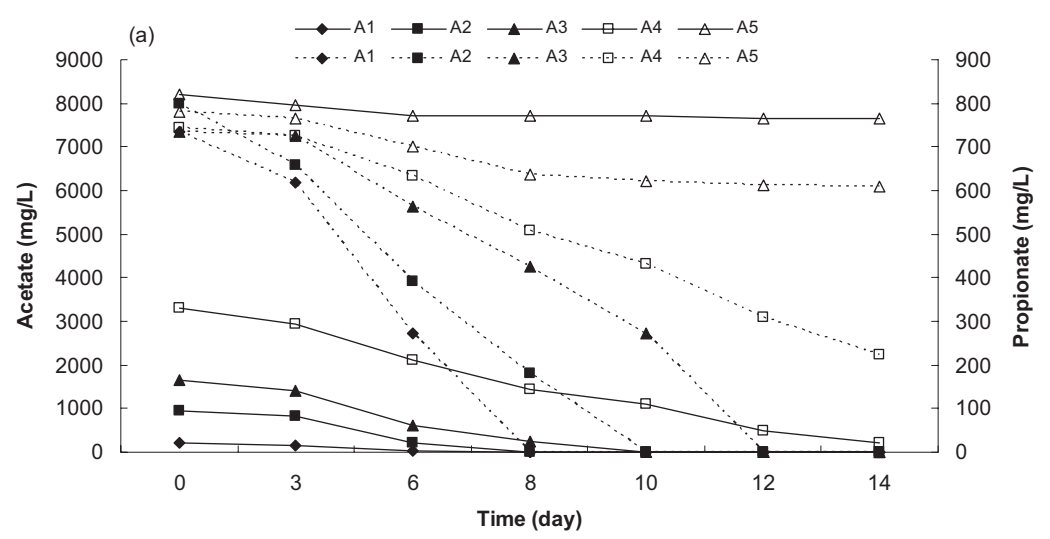

(b)

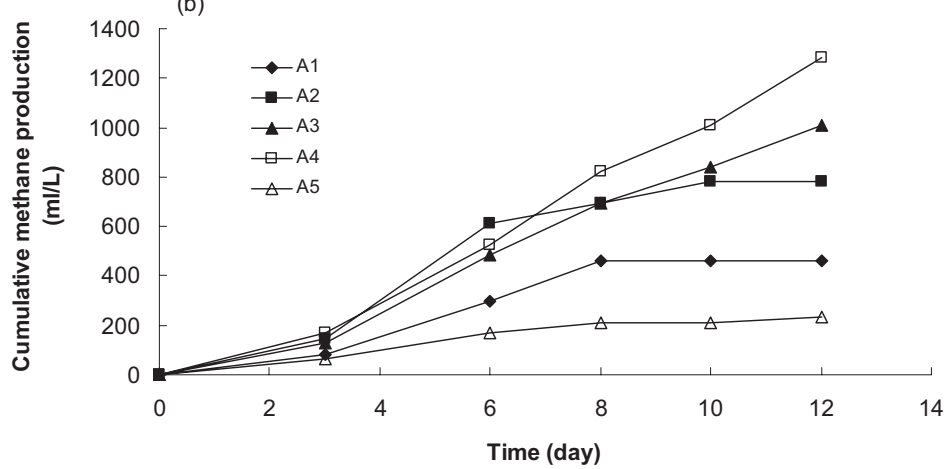

Fig. 3 Degradation curves of acetate and propionate and methane production in propionate pregrown reactors under varied initial acetate concentrations with the same initial propionate levels (about 750 $\mathrm{mg} / \mathrm{l}$ ). (a) Acetate (solid line) and propionate concentrations (dotted line), (b) Cumulative methane productions in the reactors. The initial acetate levels in the five reactors are 200(A1), 950(A2), 1650(A3), 3300(A4) and 8200(A5) mg/l, respectively.

production data in propionate pregrown reactors (Fig. 3 (b)) were in accordance with the results of acetate and propionate degradation.

Comparison between the two pregrown inocula The above results showed that the performances of acetate pre-grown reactors differed from propionate pregrown ones.

As it is known that methanogenic activities of different pregrown inocula can be compared from batch experiments using the simple formulas of Monod kinetics models ${ }^{11,25,26)}$, among which Michaelis-Menten model (equations 1 and 2) has been successfully applied in acetate and glucose pregrown cultures ${ }^{16)}$ :

$$
\begin{aligned}
& q=q_{\max } \cdot \frac{S}{S+K_{S}} \\
& \frac{1}{q}=\left(\frac{K_{S}}{q_{\max }}\right) \frac{1}{S}+\frac{1}{q_{\max }}
\end{aligned}
$$

where $q=$ specific substrate degradation rate $(\mathrm{mg} / \mathrm{g}-\mathrm{VSS} / \mathrm{d}), \quad q_{\max }=$ maximum specific substrate degradation rate $(\mathrm{mg} / \mathrm{g}-\mathrm{VSS} / \mathrm{d}), \quad S=$ substrate concentration $(\mathrm{mg} / l)$ and $K_{S}=$ saturation constant $(\mathrm{mg} / l)$. The $q_{\max }$ and $K_{S}$ values can be obtained from the intercept and slope of linear fit of $1 / q_{t}$ vs $1 / S_{t}$, and $q_{t}=X \cdot t /\left(S_{0}-S_{t}\right)$, in which $\mathrm{X}$ is biomass concentration (g-VSS/l), $S_{0}$ is initial substrate 
concentration $(\mathrm{mg} / l)$, and $S_{t}$ and $q_{t}$ are substrate concentration $(\mathrm{mg} / l)$ and specific substrate degradation rate $(\mathrm{mg} / \mathrm{g}-\mathrm{VSS} / \mathrm{d})$ at the $t^{\text {th }}$ day, respectively.

In order to make the characteristics of acetate and propionate pregrown inocula more clearly, Table 1 lists the estimated kinetic parameters $\left(q_{\max }\right.$ and $\left.K_{S}\right)$ derived from the batch experimental data (A1-A4) according to Michaelis-Menten model. From the estimated $q_{\max }$ values (Tab. 1), it was found that acetate pregrown inoculum utilized acetate 2-3 times faster than propionate pregrown inoculum did. And apparently, under the co-existence condition of $3300 \mathrm{mg} / \mathrm{l}$ acetate and $750 \mathrm{mg} / \mathrm{l}$ propionate (A4), no inhibition on acetate degradation of these two inocula can be deduced from the increased $q_{\max }$ and decreased $K_{S}$ values compared with A3, which was in agreement with the observed methane production results. Due to pre-acclimation, the obtained specific acetate or propionate degradation rate possessed by acetate or propionate pregrown inoculum was much higher than the results at different depths of UASB in the treatment of synthetic molasses wastewater by Ren et al. ${ }^{12}$.

The kinetic results indicated that propionate was more difficult to be utilized than acetate

Table 1 Kinetic data $\left(q_{\max }\right.$ and $\left.K_{S}\right)$ for the two pregrown inocula under varied initial acetate concentration and the same initial propionate (about 750 $\mathrm{mg} / \mathrm{l})$ conditions (Reactors A1-A4).

\begin{tabular}{|c|c|c|c|c|}
\hline \multirow{2}{*}{$\begin{array}{l}\text { VFA \& } \\
\text { Reactors }\end{array}$} & \multicolumn{2}{|c|}{$\begin{array}{c}\text { Acetate pregrown } \\
\text { inoculum }\end{array}$} & \multicolumn{2}{|c|}{$\begin{array}{c}\text { Propionate } \\
\text { pregrown inoculum }\end{array}$} \\
\hline & $\begin{array}{c}q_{\max } \\
(\mathrm{mg} / \mathrm{g}-\mathrm{VSS} / \mathrm{d})\end{array}$ & $\begin{array}{c}K_{S} \\
(\mathrm{mg} / \mathrm{l})\end{array}$ & $\begin{array}{c}q_{\max } \\
(\mathrm{mg} / \mathrm{g}-\mathrm{VSS} / \mathrm{d})\end{array}$ & $\begin{array}{c}K_{S} \\
(\mathrm{mg} / \mathrm{l})\end{array}$ \\
\hline \multicolumn{5}{|c|}{ I. Acetate degradation ${ }^{\mathrm{a}}$} \\
\hline A3 & 1183 & 129 & 352 & 151 \\
\hline $\mathrm{A} 4$ & 1602 & 68 & 573 & 83 \\
\hline \multicolumn{5}{|c|}{ II. Propionate degradation } \\
\hline $\mathrm{A} 1$ & 46 & 251 & 135 & 238 \\
\hline $\mathrm{A} 2$ & 81 & 173 & 188 & 124 \\
\hline A3 & 64 & 152 & 91 & 131 \\
\hline $\mathrm{A} 4$ & 47 & 145 & 71 & 102 \\
\hline
\end{tabular}

a. A1 and A2 were omitted because of their fast degradation rates and too less data could be used to make kinetic estimations. A5 was excluded from kinetic estimation because severe inhibition occurred in both pregrown systems. The initial acetate levels were 200, 950, 1650 and $3300 \mathrm{mg} / \mathrm{l}$ in $\mathrm{A} 1, \mathrm{~A} 2, \mathrm{~A} 3$ and $\mathrm{A} 4$, respectively. for both pregrown inocula, and its degradation rate was about $3-5 \%$ or $10-30 \%$ of acetate degradation rate in the same acetate or propionate pregrown reactor, respectively. As Aguilar et al. ${ }^{16)}$ pointed out, pre-contacting with propionate could improve the capability of microorganisms to degrade propionate, which can also be manifested in this study by the increased $q_{\max }$ and decreased $K_{S}$ values for propionate degradation by propionate pregrown inocula compared with acetate pregrowns. In propionate pregrown systems, although the acetate degradation rate slowed down (Tab.1), the total methane production didn't seem to decrease (Fig. 3(b)) probably due to their higher propionate degradation rates.

The $K_{S}$ values obtained in this study were among the range suggested by Pavlostathis and Giraldo-Gomez ${ }^{27)}$, e.g., $K_{S}=11-421 \mathrm{mg}$ $\mathrm{COD} / l$ for acetate and $K_{S}=12-500 \mathrm{mg} \mathrm{COD} / l$ for other VFA, which were determined by many operation parameters such as solids retention time (SRT), substrate concentration and dominant microorganisms, etc. ${ }^{26}$

All the data of methane production in Fig. 4 were based on equations (3) and (4).

$$
\begin{aligned}
& \mathrm{CH}_{3} \mathrm{COOH} \rightarrow \mathrm{CH}_{4}+\mathrm{CO}_{2} \\
& 4 \mathrm{CH}_{3} \mathrm{CH}_{2} \mathrm{COOH}+2 \mathrm{H}_{2} \mathrm{O} \\
& \rightarrow 7 \mathrm{CH}_{4}+5 \mathrm{CO}_{2}
\end{aligned}
$$

The theoretical methane yields under $35 \pm 1^{\circ} \mathrm{C}$ and $1 \mathrm{~atm}$ conditions for $1 \mathrm{~g} \mathrm{CH}_{3} \mathrm{COOH}$ and $1 \mathrm{~g} \mathrm{CH}_{3} \mathrm{CH}_{2} \mathrm{COOH}$ were about $420 \mathrm{ml}$ and $600 \mathrm{ml}$, respectively. And the methane production efficiency was calculated as the percentage of experimental methane yield to theoretical value.

It can be clearly seen that methane production rates increased from 47 to 117 $\mathrm{m} l / l$-reactor/d with the increase of initial acetate levels from 200 to $3300 \mathrm{mg} / \mathrm{l}$, respectively (Fig. 4(a)). When acetate was less than $1650 \mathrm{mg} / \mathrm{l}$ (A1-A3), the propionate pregrown inoculum exhibited better than the acetate counterpart, with 5-10 $\mathrm{m} l / l$-reactor/d higher in methane production rate. Under relative higher acetate condition (A4, 3300 $\mathrm{mg} / l$ ), no apparent inhibition on methane production was observed on both two inocula. 

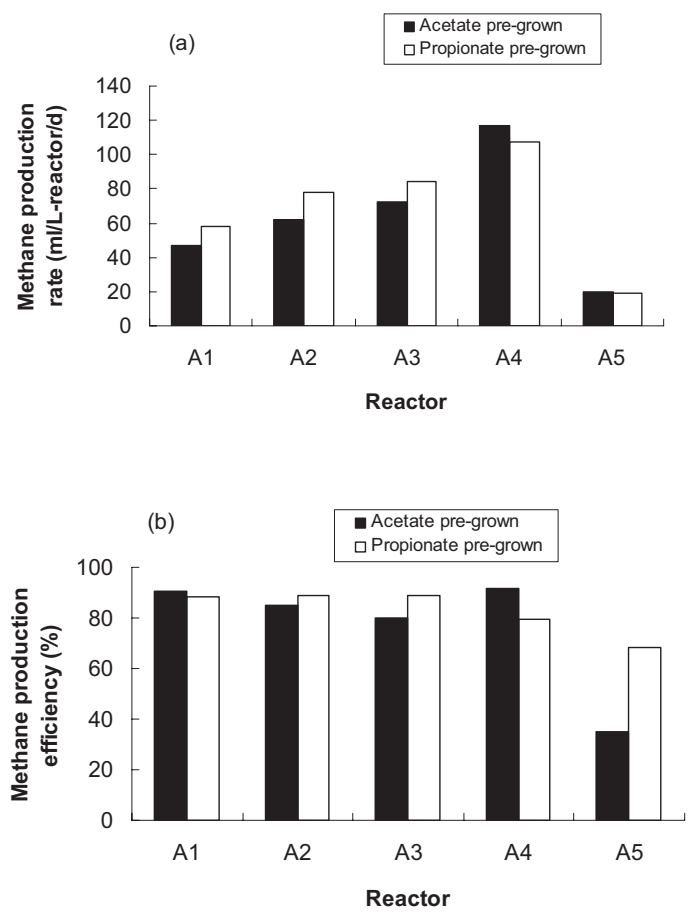

Fig. 4 Comparison of methane production for the reactors inoculated with acetate pregrown and propionate pregrown inocula, respectively, based on the first series of experiments.

However, the acetate pregrown inoculum performed a little bit better, with methane production about $9 \mathrm{~m} l / l$-reactor/d higher than the propionate pregrown. The methane production was severely inhibited for both pregrown microorganisms under the condition of $8200 \mathrm{mg} / \mathrm{l}$ of initial acetate.

According to the conversion factors for acetate and propionate to COD values, 1.066 and 1.512 , respectively ${ }^{17)}$, the methane yields for per gram of COD removed in the four normal reactors (A1-A4) ranged between 0.31 $-0.36 l$, which were comparable with the result of $0.30 l$ obtained by Lin et al. ${ }^{28)}$ with mixed acetate, propionate and butyrate as substrate. The methane yields were also very close to the theoretical values of $0.4 l$ for normal anaerobic digesters at $35^{\circ} \mathrm{C}^{29}$. With the results of $80-92 \%$ of methane production efficiencies being considered (Fig. 4 (b)), about 10-20\% of VFAs might be converted to cells, which was similar with the results of Öztürk under thermophilic conditions ${ }^{23)}$. The slower decrease of methane production efficiency for propionate pregrown inoculum from A4 to A5 could partly be attributed to the rich bacteria populations, probably resulting in improved tolerance with detrimental environment (higher level of acetate in this study). This needs more detailed investigation in the future.

VFA degradation stability for the two pregrown inocula Figure 5 depicts the variations of acetate and propionate concentrations in the reactors (P1-P5) under varied initial propionate concentration and the same initial acetate $(3000 \mathrm{mg} / l)$ conditions in the second series of batch experiments, from which the kinetic estimations of $q_{\max }$ and $K_{S}$ for the two pregrown inocula were summarized in Table 2 .

From Table 2, no remarkable difference at acetate degradation was discovered for these two kinds of systems under lower initial propionate levels $(0 \mathrm{mg} / \mathrm{l}$ in $\mathrm{P} 1$ and $200 \mathrm{mg} / \mathrm{l}$ in P2). However, higher level of propionate did affect acetate degradation, especially under the conditions of initial propionate levels greater than $750 \mathrm{mg} / l$ (P4 and P5).

Propionate is degraded by syntrophic consortia of acetogenic bacteria and methanogenic bacteria ${ }^{23,30)}$. Although $\mathrm{pH}$ and temperature were controlled in the same way in these two series of experiments, less and much slower of propionate degradation was observed in the second batch experiments (Tables 1 and 2), probably due to different initial conditions of the experiments, in which the bacterial population composition might be the major reason. It was noticed in Table 2 that propionate degradation slowed down for both inocula (with smaller values of $q_{\max }$ ) at all initial propionate levels, which might also indicate that propionate degraders were sensitive to some disturbances in the cultures, resulting in some variance of microbial populations and less stability of degradation performance.

The stable acetate degradations shown in Tables 1 and 2 implied that the acetate degradation potentials of microorganisms (including both pregrown inocula) could be relatively easier and successfully attained under controlled $\mathrm{pH}$ and temperature 

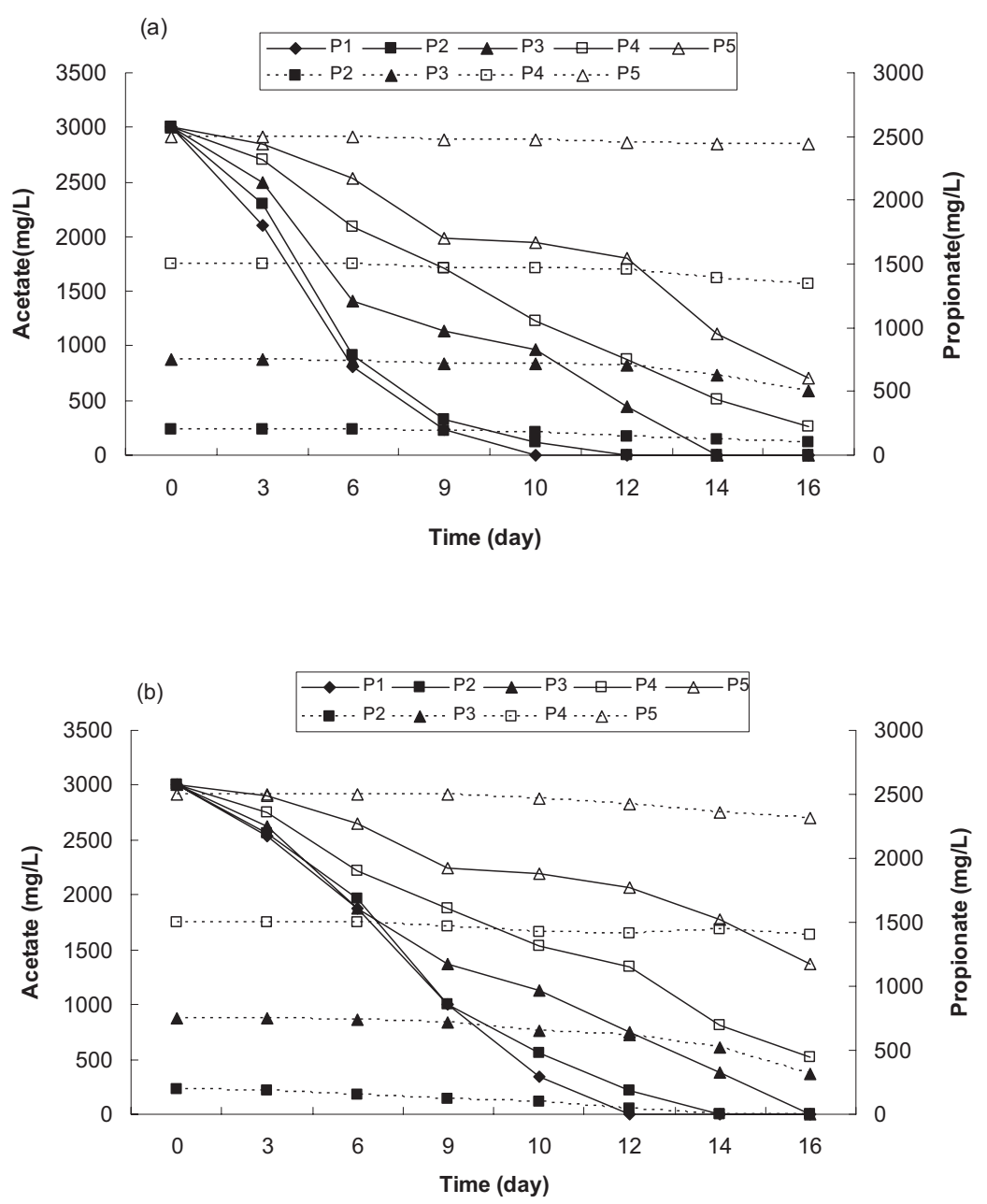

Fig. 5 Progress curves of acetate (solid line) and propionate (dotted line) concentrations in the reactors with acetate and propionate pregrown inocula inoculated under varied initial propionate concentration and the same initial acetate levels $(3000 \mathrm{mg} / \mathrm{l})$. (a)Acetate pre-grown inoculated reactors; (b) Propionate pre-grown inoculated reactors. The initial propionate levels are 0 (P1), 200 (P2), 750 (P3), 1500 (P4) and 2500 (P5) $\mathrm{mg} / \mathrm{l}$, respectively.

conditions. However, the performance of propionate degradation for both inocula still needs us to pay more attention and find some other effective measures to control, even though Wang et al. $^{31)}$ has discovered that acetate degradation was independent of the presence of propionate in the anaerobic digestion of wasted activated sludge, while the opposite was not the case. Such additional information as more accurate variation of $\mathrm{pH}, \mathrm{H}_{2}$ partial pressure in biogas and effect of operation mode (continuous or semi- continuous) will be very important and useful for us in the further investigation of this complex process.

Effects of initial conditions on the digestion performance of the pre-grown systems As discussed above, the pregrown microorganisms exhibited stable and effective performance of acetate degradation if acetate and propionate levels being controlled less than $3300 \mathrm{mg} / \mathrm{l}$ and $750 \mathrm{mg} / \mathrm{l}$ in the reactors, respectively, and propionate degradation potential might be unstable due to some disturbances occurred 
Table 2 Kinetic data $\left(q_{\max }\right.$ and $\left.K_{s}\right)$ for the two pregrown inocula under varied propionate concentration and the same initial acetate $(300 \mathrm{mg} / \mathrm{l})$ conditions (Reactors P1-P5).

\begin{tabular}{cccccc}
\hline & \multicolumn{2}{c}{$\begin{array}{c}\text { Acetate pre-grown } \\
\text { inoculum }\end{array}$} & & \multicolumn{2}{c}{$\begin{array}{c}\text { Propionate pre- } \\
\text { grown inoculum }\end{array}$} \\
\cline { 2 - 3 } Reactors & $\begin{array}{c}q_{\max } \\
(\mathrm{mg} / \mathrm{g}-\mathrm{VSS} / \mathrm{d})\end{array}$ & $\begin{array}{c}K_{S} \\
(\mathrm{mg} / l)\end{array}$ & & $\begin{array}{c}q_{\max } \\
(\mathrm{mg} / \mathrm{g}-\mathrm{VSS} / \mathrm{d})\end{array}$ & $\begin{array}{c}K_{S} \\
(\mathrm{mg} / l)\end{array}$ \\
\hline I. Acetate & $\begin{array}{c}\text { degradation } \\
\text { I. }\end{array}$ & & & \\
P1 & 1873 & 133 & & 580 & 121 \\
P2 & 1883 & 157 & & 539 & 124 \\
P3 & 1172 & 80 & & 603 & 42 \\
P4 & 470 & 64 & & 391 & 67 \\
P5 & 234 & 98 & & 158 & 104 \\
\hline II. Propionate degradation & & & & \\
P2 & 4 & 135 & & 18 & 133 \\
P3 & 7 & 130 & & 7 & 152 \\
P4 & 7 & 124 & & 16 & 47 \\
P5 & 10 & 60 & & 7 & 130 \\
\hline
\end{tabular}

a. P1 was excluded from kinetic estimation in propionate degradation due to no propionate contained. The propionate levels were $0,200,750,1500$ and $2500 \mathrm{mg} / \mathrm{l}$ in $\mathrm{P} 1, \mathrm{P} 2, \mathrm{P} 3, \mathrm{P} 4$ and $\mathrm{P} 5$, respectively. in the systems. The performance difference between these two pregrown systems and between acetate and propionate degradations may be largely attributed by different microbial compositions in these two systems and different pathways for the methanogenesis of acetate and propionate.

Besides the above two important factors, initial conditions in the reactors can also influence the digestion performance to some extent. According to the experiment conditions in this study, two of the initial conditions should be mentioned. One was initial propionate/acetate (P/A) ratio, and the other was initial VFA load.

Figures 6 and 7 illustrates the average acetate and propionate degradation rates vs initial P/A ratio and initial VFA load in all the reactors in this study (A1-A4 and $\mathrm{P} 1$ -P5), respectively, except A5 because of severe inhibition. The average acetate

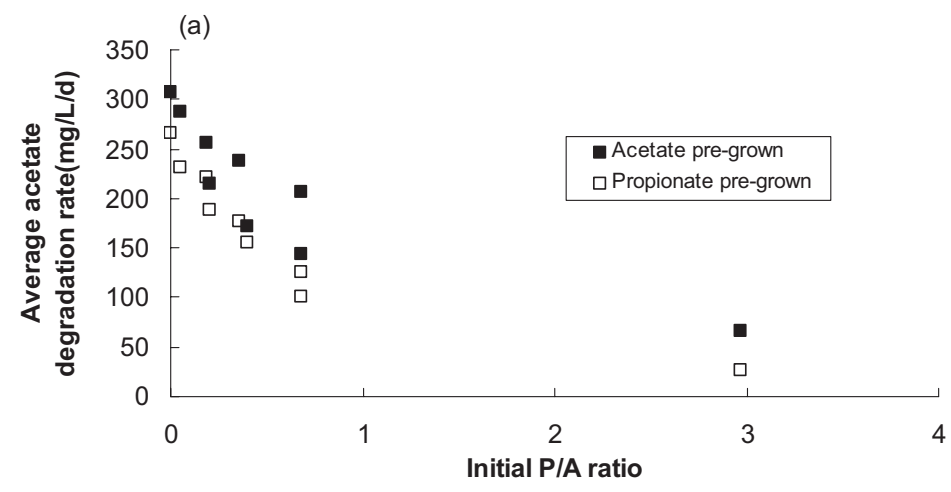

(b)

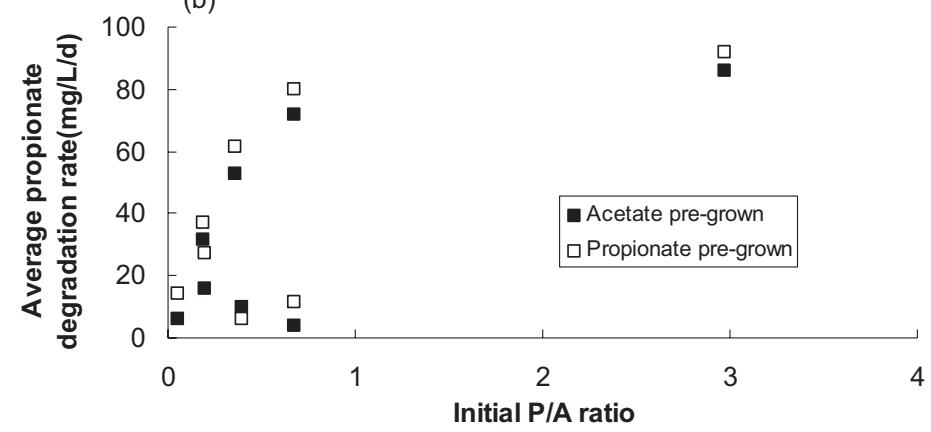

Fig. 6 Effect of initial P/A ratio on average acetate and propionate degradation rates in these two pregrown systems (A1-A4, P1-P5). (a) Average acetate degradation rate; (b) Average propionate degradation rate. A5 is excluded from the data because of severe inhibition, and propionate level used in P/A ratio is as acetate. 


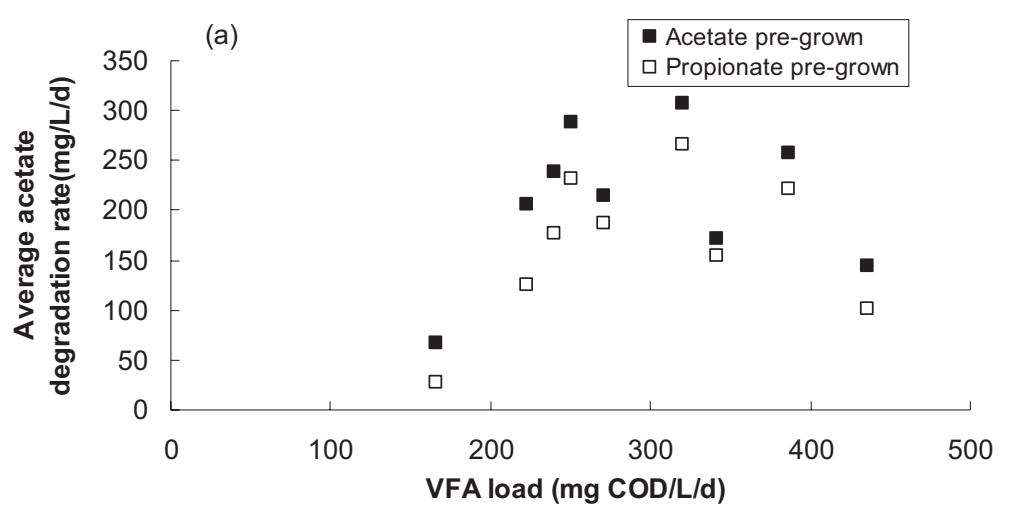

(b)

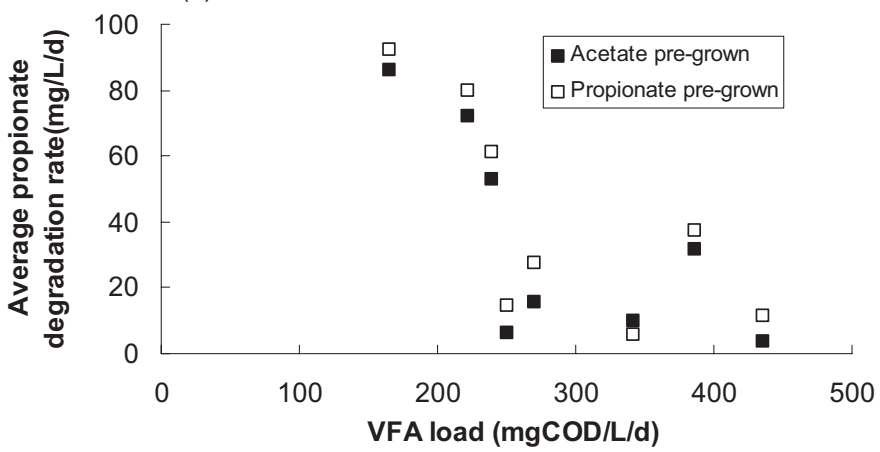

Fig. 7 Effect of initial VFA load on average acetate and propionate degradation rates in these two pregrown systems (A1-A4, P1-P5). (a) Average acetate degradation rate; (b) Average propionate degradation rate. $A 5$ is excluded from the data because of severe inhibition.

degradation rate had a moderate negative correlation with initial P/A ratio for both pregrown inocula (Fig. 6 (a), correlation coefficients $\mathrm{R}^{2}=0.72-0.75$ ) and the acetate pregrown microorganisms usually utilized acetate $30-50 \mathrm{mg} / \mathrm{l}-$ reactor/d faster $(66.7$ $-307.2 \mathrm{mg} / \mathrm{l}$-reactor/d) than the propionate pregrowns did (26.7-265.7 $\mathrm{mg} / \mathrm{l}$-reactor/d). However, probably due to the difficulty and instability of propionate degradation, such effectiveness was not obtained for propionate degradation rate in propionate pregrown system. Anyway, 5-10 mg/l-reactor/d more of propionate can be degraded in propionate pre-grown systems than in acetate pre-grown systems.

Seen from Fig.7, the two VFA degradation rates seemed to change with initial VFA load in a different way. The average acetate degradation rates for the two pre-grown systems firstly increased with the increase of VFA load, and reached at their highest values (about $300 \mathrm{mg} / \mathrm{l}$-reactor/d) at about $300 \mathrm{mg}$ $\mathrm{COD} / l$-reactor/d of VFA load (Fig. 7 (a)), while the average propionate degradation rates seemed to have a weak negative correlation with the initial VFA load (Fig. 7 (b), correlation coefficients $R^{2}=0.50-0.53$ ). The information of performance varied with these initial conditions could aid us in the optimal design and effective operation of anaerobic digesters in the future research and practice.

\section{CONCLUSION}

Acetate and propionate play important roles in methanogensis of complex organic substances in anaerobic digesters. The following conclusion can be drawn from this study: 
(1)Effective and stable acetate degradations can be easily obtained and maintained in both pregrown systems if initial acetate and propionate concentrations less than 3300 $\mathrm{mg} / l$ and $750 \mathrm{mg} / l$, respectively.

(2)Propionate degradation starts only when initial acetate being degraded completely and the performances of propionate degradation for both pregrown inocula were unstable probably due to the sensitivity of propionate degraders to some disturbances.

(3)Although different bacterial populations were possibly contained in these two pregrown inocula, which exhibited different acetate or propionate degradation rates, no distinctive differences were discovered for the two kinds of pregrown systems with respect to methane production under the same initial conditions.

(4)In normally operated reactors, acetate and propionate degradation rates have some negative correlations with the initial P/A ratio and VFA load, respectively. The kinetics estimations with the batch experimental data can also give us an insight into the complicated methanogensis of mixed acetate and propionate substrate by pregrown inocula.

\section{ACKNOWLEDGEMENTS}

The work was supported by the Strategic Japanese-Chinese Cooperative Programme on "Material Technology for Environmental Conservation and Advanced Utilization of Energy".

\section{REFERENCES}

1 ) Cheong D.-Y. and Hansen C.L.: Effect of feeding strategy on the stability of anaerobic sequencing batch reactor responses to organic loading conditions, Bioresource Technol., 99, 5058-5068 (2008)

2 ) Gallert C. and Winter J.: Propionic acid accumulation and degradation during restart of a full-scale anaerobic biowaste digester, Bioresource Technol., 99, 170 $-178(2008)$

3 Leitao R. C., van Haandel A. C., Zeeman G., and Lettinga G.: The effects of operational and environmental variations on anaerobic wastewater treatment systems: A review,
Bioresource Technol., 97, 1105-1118 (2006)

4) Mechichi T. and Sayadi S.: Evaluating process imbalance of anaerobic digestion of olive mill wastewaters, Process Biochem., 40, 139-145 (2005)

5 ) Nielsen H.B., Uellendahl H., and Ahring B.K.: Regulation and optimization of the biogas process: Propionate as a key parameter, Biomass Bioenerg., 31, 820-830 (2007)

6 ) Hill D.T., Cobb S.A., and Bolte J.P.: Using volatile fatty acid relationships to predict anaerobic digester failure, T. ASAE., 30, 496-501 (1987)

7 ) Hill D.T. and Holmberg R.D.: Long chain fatty acid relationships in anaerobic digestion of swine waste, Biol. Waste., 23(3), 195-214 (1988)

8 ) Horiuchi J.-H., Shimizu T., Tada K., Kanno T., and Kobayashi M.: Selective production of organic acids in anaerobic acid reactor by $\mathrm{pH}$ control, Bioresource Technol., 82, 209-213 (2002)

9 ) Feitkenhauer H., Sachs J. V., and Meyer U.: On-line titration of volatile fatty acids for the process control of anaerobic digestion plants, Water Res., 36, 212-218 (2002)

10) Smith P.H. and Mah R.A.: Kinetics of acetate metabolism during sludge digestion, Appl. Microbiol., 14, 368-371 (1966)

11) Lawrence A.W. and McCarty P.L.: Kinetics of methane fermentation in anaerobic treatment, J. Wat. Pollut. Control Fed., 41, 1-17 (1969)

12) Ren N., Liu M., Wang A., Ding J., and Li H.: Organic acids conversion in methanogenicphase reactor of the two-phase anaerobic process, Environ. Sci., 24(4): 89-93 (2003) (in Chinese)

13) Fischer J.R., Iannotti E.L., and Porter J.H.: Anaerobic digestion of swine manure at various influent solids concentrations, Agr. Wastes., 11(3), 157-166 (1984)

14) Kaspar H.F. and Wuhrmann K.: Production inhibition in sludge digestion, Microbiol. Ecol., 4, 241-248 (1978)

15) van den Berg L.A. and Lentz C.P.: Anaerobic digestion of pear waste: laboratory equipment design and preliminary results, J. Can. Inst. Food Technol., 4, 159-165 (1977)

16) Aguilar A., Casas C., and Lema J.M.: 
Degradation of volatile fatty acids by differently enriched methanogenic cultures: kinetics and inhibition, Water Res., 29(2), 505-509 (1995)

17) Oktem Y.A., Ince O., Donnelly T., Sallis P., and Ince B.K.: Determination of optimum operating conditions of an acidification reactor treating a chemical synthesisbased pharmaceutical wastewater, Process Biochem., 41, 2258-2263 (2006)

18) Jiang Z. (Ed.): Environmental Engineering ( $2^{\text {nd }}$ Edition), Higher Education Press, Beijing, pp 19. (2005) (in Chinese)

19) Yang Y., Tada C., Miah M.S., Tsukahara K., Yagishita T., and Sawayama S.: Influence of bed materials on methanogenic characteristics and immobilized microbes in anaerobic digester, Mater. Sci. Eng. C., 24, 413-419 (2004)

20) Uemura S. and Harada H.: Microbial characteristics of methanogenic sludge consortia developed in thermophilic UASB reactor, Appl. Microbiol. Biotech., 39, 654 -660 (1993)

21） Mösche M. and Jördening H.-J.: Comparison of different models of substrate and product inhibition in anaerobic digestion, Water Res., 33(11), 2545-2554 (1999)

22) Lange M., and Ahring B.K.: A comprehensive study into the molecular methodology and molecular biology of methanogenic Archaea, FEMS Microbiol. Rev., 25, 553 $-571(2001)$

23) Öztürk M.: Conversion of acetate, propionate and butyrate tomethane under thermophilic conditions in batch reactors, Water Res., 25, 1509-1513 (1991)
24) Mawson A.J., Earle R.L., and Larsen V.F.: Degradation of acetic and propionic acids in the methane fermentation, Water Res., 25(12), 1549-1554 (1991)

25) Smith M.R. and Mah R.A.: Growth and methanogenesis by Methanosarcina strain 227 on acetate and methanol, Appl. Environ. Microbiol., 36, 870-879 (1978)

26) Vavilin V.A. and Lokshina L.Y.: Modeling of volatile fatty acids degradation kinetics and evaluation of microorganism activity, Bioresource Technol., 57, 69-80 (1996)

27) Pavlostathis S.G. and Giraldo-Gomez E.: Kinetics of anaerobic treatment, Crit. Rev. Environ. Control., 21, 411-490 (1991)

28) Lin C.-Y., Sato K., Noike T., and Matsumoto J.: Methanogenic digestion using mixed substrate of acetic, propionic and butyric acids, Water Res., 20(3), 385-394 (1986)

29) Metcalf \& Eddy, Inc.: Wastewater Engineering: Treatment and Reuse ( $4^{\text {th }}$ Edition, gravure version), Qsinghua University Press, Beijing, pp993 (2003)

30) Ahring B.K., Ibrahim A.A., and Mladenovska Z.: Effect of temperature increase from 55 to $65 \mathrm{C}$ on performance and microbial population dynamics of an anaerobic reactor treating cattle manure, Water Res., 35, 2446-2452 (2001)

31) Wang Q., Kuninobu M., Ogawa H.I., and Kato Y.: Determination of volatile fatty acids in highly efficient anaerobic digestion, Biomass Bioenerg., 16, 407-416 (1999)

(Submitted 2008. 4. 30)

(Accepted 2008. 5. 27) 
